\title{
PATRIMÔNIOS E CONFLITOS DE UM AFOXÉ NA REURBANIZAÇÃO DA REGIÃO PORTUÁRIA CARIOCA ${ }^{1}$
}

Roberta Sampaio Guimarães

Em março de 2011, pesquisas arqueológicas desenvolvidas durante as obras para a "revitalização urbana" da região portuária do Rio de Janeiro encontraram lajes de pedra e diversos objetos, como búzios, miçangas, cachimbos, anéis e cristais, pertencentes aos mais de 500 mil africanos escravizados que haviam aportado no antigo Cais do Valongo. Os jornais cobriram o acontecimento com entusiasmo e os objetos foram salvaguardados pelo Instituto do Patrimônio Histórico e Artístico Nacional (Iphan). Lideranças de religiões de matriz africana foram convocadas para dar inteligibilidade ao achado e confirmar o caráter sagrado daquela terra chamada por todos de "Pequena África". ${ }^{2}$

Logo a Prefeitura remodelou o local, ergueu um Memorial e criou o Circuito Histórico e Arqueológico da Herança Africana, que indicava outros pontos de visitação referentes ao passado escravista da região, como a Pedra do Sal, o Jardim Suspenso do Valongo, o largo do Depósito (atual praça dos Estivadores), o Cemitério dos Pretos Novos e o Centro Cultural José Bonifácio. Candomblecistas, capoeiristas, baianas de acarajé e integrantes de escolas de samba passaram a realizar um ritual de lavagem simbólica do cais, que foi incorporado ao calendário oficial da cidade. Em 2014, o Memorial foi apresentado como candidato a Patrimônio Histórico da Humanidade junto à Organização das Nações Unidas para a Educação, a Ciência e a Cultura (Unesco), com decisão final do pedido prevista para julho de $2017 .^{3}$

Neste artigo, reflito sobre os efeitos da reurbanização da região portuária carioca sobre o Afoxé Filhos de Gandhi, bloco carnavalesco referenciado nas práticas do candomblé. Busco compreender como o bloco organizou um pleito de reconhecimento patrimonial a partir da construção narrativa da Pequena África na tentativa de regularizar e reformar o sobrado de sua sede de ensaios, mas não encontrou apoio governamental ou privado porque o imóvel foi classificado como "em ruínas e invadido". Exploro a hipótese de que o não reconhecimento se deveu, por um lado, ao fato de que esses setores 
privilegiaram investir em narrativas sobre um passado mítico relacionado à oralidade e à religiosidade africanas, como no caso do Cais do Valongo, o que dissociava as ações patrimoniais e turísticas das demandas habitacionais do tempo presente. Mas se deveu também a disputas dos integrantes do bloco sobre suas concepções de patrimônio, que reverberavam diferentes experiências e memórias coletivas do povo do santo.

\section{O projeto urbano para a região portuária carioca}

As obras de reurbanização da região portuária começaram nos anos 1990, com a emergência entre planejadores urbanos da Prefeitura do conceito de projeto urbano. ${ }^{4}$ Em consonância com a crítica à produção arquitetônica modernista e ao urbanismo funcionalista que vinham sendo implantados nas grandes cidades (Jacobs 2011; Gorelick 2005), esse conceito propunha incentivar a requalificação do espaço público, criar novas centralidades e reabilitar conjuntos arquitetônicos reconhecidos como importantes patrimônios do ambiente cultural. No Rio de Janeiro foram ainda incluídos objetivos como o apoio às parcerias entre setores públicos e privados e o combate à "desordem urbana" (Barandier 2006), este último apoiado no imaginário que representava a cidade como violenta e territorialmente partida entre "favela e asfalto" e moralmente oposta entre "marginalizados e civilizados" (Leite 1995; Pacheco de Oliveira 2014). ${ }^{5}$

Entre as diversas medidas implantadas, um conjunto expressivo incidiu sobre a região portuária carioca após a aprovação do Plano Estratégico da Cidade do Rio de Janeiro em 1995, que permitiu à iniciativa privada financiar e explorar equipamentos urbanos e desenvolver negócios imobiliários em amplos terrenos industriais desativados (Compans 1998). Nesse contexto, a patrimonialização do "sítio histórico" da região pelo projeto Sagas (acrônimo dos bairros portuários da Saúde, Gamboa e Santo Cristo) entre os anos de 1983 e 1988 cumpriu um papel central de legitimação social. O Sagas havia protegido mais de 2 mil bens entendidos como símbolos de identidades culturais - como murais de botecos portugueses, sobrados coloniais e cortiços da época do Império - e restringido usos tidos como sujos e inadequados, como os de depósitos, oficinas, frigoríficos e garagens (Guimarães 2016).

Além de identificar valores culturais, as classificações do Sagas também produziram novas realidades, sendo utilizadas para segmentar ações urbanísticas na região portuária. No conjunto de circunstâncias de implantação do projeto urbano carioca, a definição do que era e do que não era histórico e cultural pela retórica patrimonial fixou fronteiras simbólicas e territoriais 
e redistribuiu os espaços portuários. Dessa forma, nos morros da Conceição, da Saúde, do Livramento e do Pinto, onde ficaram todos os bens protegidos, foram incentivados o turismo e a atração residencial da classe média através de ações de recuperação física de sobrados e de identificação de "vazios" a serem ocupados, como nos projetos Reabilitação de Cortiços (1996-1998), Habitacional da Saúde (1996-2001) e Reabilitação de Sítios Históricos (2000). Já nas áreas planas que circundavam esses morros foram retiradas moradias construídas debaixo de viadutos, criadas ou reformadas praças e largos e restringida a atuação de vendedores ambulantes. Os efeitos do Sagas podem ser ainda mais bem compreendidos quando observadas também as políticas implantadas nos locais contíguos a esses morros que foram excluídos da ação patrimonial. O morro da Providência, embora tenha entrado na área tutelada da Gamboa, não teve bens tombados ou preservados como nos demais morros. E nenhum bem do bairro portuário do Caju foi protegido. Neles foi desenvolvido o programa Favela-Bairro, visando dotar essas localidades de infraestrutura urbana, serviços, equipamentos públicos e políticas sociais.

Tais projetos foram unificados e ampliados pela Prefeitura em 2001, através do Porto do Rio - Plano de Recuperação e Revitalização da Região Portuária do Rio de Janeiro. Além da reestruturação de ruas e logradouros, foi construído o centro poliesportivo Vila Olímpica da Gamboa (2005) e o centro de produção de desfiles carnavalescos Cidade do Samba (2006). Mas o principal projeto idealizado para catalisar a transformação da região em polo turístico não foi executado: a construção de filial do Museu Guggenheim, instituição nova-iorquina prestigiada por sua presença em cidades como Bilbao, Berlim e Veneza, que teve o contrato contestado por vereadores e os princípios construtivos criticados por seu "caráter shopping center", já que previa a instalação de centros comerciais e estacionamento.

Vultosos investimentos financeiros ocorreram apenas a partir de 2009, com a eleição da cidade para sediar a Copa do Mundo 2014 e as Olimpíadas 2016. Projetos de mobilidade, infraestrutura, segurança pública e patrimônio concentraram-se então no Porto Maravilha - Operação Urbana Consorciada da Área de Especial Interesse Urbanístico da Região Portuária do Rio de Janeiro. Os locais tidos como favelizados ou perigosos receberam políticas de repressão e controle sob o argumento de expulsar o tráfico de drogas e garantir segurança e cidadania a seus moradores, como o caso da Unidade de Polícia Pacificadora instalada no Morro da Providência (2010). Dois grandes equipamentos urbanos foram construídos, o Museu de Arte do Rio (2013) e o Museu do Amanhã (2015), ambos voltados para o entretenimento e a difusão de conteúdo artístico, científico e pedagógico. Ademais, em 2014, o elevado automobilístico da Perimetral foi demolido, a Via Binário foi inau- 
gurada e começou-se a construção do sistema de Veículo Leve sob Trilhos, obras que deslocaram o tráfego de automóveis para as ruas internas da região e possibilitaram a fruição paisagística da orla da Baía de Guanabara e a valorização dos terrenos e armazéns que a margeavam.

Como ocorrido em outras áreas portuárias do mundo classificadas como patrimônios culturais e/ou sítios históricos, nos últimos 25 anos os espaços portuários cariocas foram ressignificados, atraindo jovens de classe média, artistas plásticos, ONGs, associações recreativas e culturais, bares, casas de shows e edifícios corporativos. Seus habitantes também tiveram suas formas de organização social alteradas, com os ritmos e as extensões da transformação sendo ditados tanto pelos novos fluxos urbanos quanto pela proliferação de conflitos e variadas formas de adesão, resistência e subversão às intervenções urbanas.

No jogo de rupturas e continuidades com as experiências de passado e os projetos de futuro, alguns propuseram, por exemplo, formas de luta pela moradia popular através da resistência a programas de remoção (Gutterres 2014) ou da ocupação de prédios governamentais desativados (Birman, Fernandes \& Pierobon 2014). Novos habitantes tiveram suas atividades constrangidas por moradores e movimentos sociais que os acusavam de elitizar a região, como no caso dos artistas plásticos que instalaram ateliês em sobrados ou antigas fábricas como a Bhering (Bordenave 2014). E entre movimentos sociais e organizações civis que se identificavam como portadores da cultura e da memória afro-brasileiras da região, uma narrativa específica atendeu a diferentes expectativas e demandas: a Pequena África.

\section{O processo de patrimonialização da Pequena África}

Durante a reurbanização da região portuária, as narrativas sobre a Pequena África operaram com um conjunto comum de demarcações espaciais e temporais: a chegada e a comercialização de escravos africanos no Valongo durante os séculos XVIII e XIX; a ocupação de casas do bairro da Saúde por baianos e do entorno da Pedra do Sal por africanos a partir de meados do século XIX; o deslocamento desses habitantes para o bairro da Cidade Nova, favelas e subúrbios ${ }^{6}$ da cidade, causado pela reforma urbana propalada modernizadora do prefeito Pereira Passos no início do século XX, que demoliu inúmeros imóveis da região portuária sob o pretexto de higienizar física e moralmente espaços e habitantes (Carvalho 2001; Chalhoub 1996).

Afora essas demarcações consensuais, a definição da Pequena África apresentava grande variabilidade de acordo com cada contexto em que 
era evocada, podendo abranger outras situações do passado e mesmo do tempo presente e também diferentes locais de moradia e sociabilidade. Essa maleabilidade sugeria que a noção não se referia propriamente a um local concreto, mas sobretudo a um espaço utópico (Foucault 2001), onde a sociedade era concebida de forma aperfeiçoada e baseada em um modelo ideal de ancestralidade, identidade e religiosidade africanas. A narrativa da Pequena África era, portanto, socialmente eficaz porque remetia ao ideal de uma "cidade negra", que abarcava tanto um passado de resistências quanto projeções de um futuro no qual seriam superados os males, os traumas e as exclusões produzidos pela escravidão.

A narrativa da Pequena África havia sido produzida no período de redemocratização brasileira (1979-1989), marcado pelo fortalecimento dos partidos de esquerda, a reorganização da sociedade civil, as celebrações dos 100 anos de abolição da escravidão e a formação da Assembleia Constituinte de 1988. Estes eventos propiciaram um ambiente de discussão sobre as dificuldades de inserção econômica do negro no sistema de classes e das barreiras sociais enfrentadas por causa do preconceito racial e do racismo. Entre a geração que durante o período atuou nos movimentos negros, a crítica à democracia racial e sua ideologia de convivência harmoniosa inter-racial passou a ser usada como instrumento de luta em prol da afirmação étnico-cultural (Guimarães 2001).

Difundiram-se então principalmente as matrizes de pensamento que propunham a valorização da "origem africana" do negro brasileiro como instrumento de ação política, com destaque para a atuação de Abdias do Nascimento na fundação do jornal Quilombo; do movimento literário Négritude, que no contexto de intensificação das lutas pela libertação colonial dos países africanos após a Segunda Guerra Mundial reunia produções de poetas negros de língua francesa e propunha uma perspectiva contraposta à cultura ocidental; e dos movimentos norte-americanos Black Power e Panteras Negras, que propunham ações políticas em prol de direitos civis e igualdade racial (Alberti \& Pereira 2007).

Um dos desdobramentos dessa mobilização se deu no âmbito dos processos de preservação patrimonial. Por serem considerados importantes produtores de símbolos coletivos, houve pressão política para que os tombamentos federais incluíssem bens perpetuadores da memória afro-brasileira, como crítica a uma memória nacional construída unicamente em torno das experiências da "elite branca" e de edificações católicas, militares e governamentais. Dois emblemáticos tombamentos foram realizados: da Casa Branca do Engenho Velho em Salvador/ BA, que se tornou em 1984 o primeiro terreiro de candomblé reconhecido como patrimônio 
nacional; e do Conjunto Histórico e Paisagístico de Serra da Barriga/AL, tombado em 1985 como representante da resistência escrava do Quilombo dos Palmares.

No Rio de Janeiro, um dos meios de reavivar a memória da "cidade negra" foi o livro Tia Ciata e a Pequena África no Rio de Janeiro, publicado pelo cineasta Roberto Moura em 1983. ${ }^{7}$ Ele reuniu e organizou dramaticamente um conjunto de genealogias, mitos de origem, ancestrais sagrados e deuses referentes à população de negros africanos e baianos que haviam habitado as regiões central e portuária durante as primeiras décadas do século XX. Tia Ciata era a personagem que conduzia a narrativa: quituteira e mãe de santo, sua casa na praça Onze, bairro da Cidade Nova, congregou sambistas de projeção no mercado fonográfico, como Donga, Pixinguinha, João da Baiana e Heitor dos Prazeres.

Como fontes de pesquisa, Moura utilizou contos, romances, textos acadêmicos, jornais, legislações municipais, letras de música, depoimentos de sambistas ao projeto Vozes assombradas do museu (Museu da Imagem e do Som/ RJ, 1970) e entrevistas realizadas na década de 1970 com descendentes de Ciata e com uma de suas irmãs de santo. Algumas das obras literárias retrataram o "mundo dos feitiços", como no livro As religiões no Rio (1904), de João do Rio. Outras fizeram menção à Cidade Nova como bairro ocupado principalmente por "homens de cor" no início do século, como no livro de crônicas de Lima Barreto, Feiras e Mafuás (1953). No romance Macunaíma (1928), de Mário de Andrade, foram ainda mencionados os sambistas e os religiosos do candomblé que se reuniam em torno da "feiticeira" Tia Ciata. Mas em nenhuma dessas obras aparece uma citação direta à Pequena África. E, embora seja atribuído a Heitor dos Prazeres o cunho do termo para designar a região que "se estendia da zona do cais do porto até a Cidade Nova, tendo como capital a praça Onze" (Moura 1995:93), no depoimento arquivado no Museu da Imagem e do Som o sambista de fato não cita a expressão.

Assim, tudo leva a crer que a noção de Pequena África foi inventada pelo próprio Roberto Moura, a partir de uma condensação narrativa de diferentes relatos capaz de instrumentalizar politicamente a construção de um discurso de afirmação étnico-racial na cidade. Já fazendo referência ao termo Pequena África, o relatório histórico de tombamento da Pedra do Sal foi apresentado ao Instituto Estadual de Patrimônio Cultural em 1984, afirmando ser o local representante da tradição dos orixás, do catolicismo popular, da migração dos baianos e africanos e da criação dos ranchos carnavalescos. Também na região portuária, logo depois foi inaugurado o Centro Cultural Municipal José Bonifácio (1986) com o intuito de preservar 
e difundir a memória negra. Dois marcos territoriais foram ainda criados na praça Onze: o Sambódromo (1985), que abrigou os desfiles das escolas de samba, e o monumental busto de ferro do líder antiescravista Zumbi dos Palmares (1986).

Levando-se em conta tanto o sítio histórico criado pelo projeto Sagas quanto a narrativa da Pequena África e os marcos territoriais da "memória da cidade negra", não seria exagero afirmar que a região portuária vivenciou na década de 1980 um boom de lugares de memória (Nora 1993). Uma memória entendida como direito, dever e forma de poder a ser utilizada contra a sensação de ruptura com a ordem do tempo, de crise e descontinuidade das experiências sociais. Uma necessidade de deixar rastros dessas experiências passadas em monumentos, memoriais, arquivos e centros de pesquisa, mantendo uma vigilância comemorativa em festas e rituais oficiais, ou seja, de produzir mediações para que a memória vivida se tornasse história, ainda que incompleta, petrificada e problemática.

Essa intensificação dos processos de conversão de memórias coletivas em discurso histórico preocupado com os diversos grupos que compunham a sociedade não ocorreu isoladamente no Brasil ou ficou restrita às populações afrodescendentes. Tal fenômeno de caráter revisionista teve seu ápice na década de 1980, como parte de um grande rearranjo global relacionado, entre outros eventos, aos debates sobre o Holocausto e os presos políticos desaparecidos nos períodos ditatoriais latino-americanos; à queda do muro de Berlim e à unificação da Alemanha; ao fim da União Soviética e ao início dos conflitos nos países do Leste europeu; e à formação de comissões de verdade e reconciliação na África pós-apartheid (Huyssen 2000).

Esses eventos produziram reflexões sobre o "problema do tempo" (Hartog 2006): a tentativa de compreender como as sociedades se relacionam de diferentes formas com suas experiências sobre o passado, o presente e o futuro para formar uma consciência de si como comunidade humana. Viu-se então uma obsessão pela identificação de patrimônios, referentes desde o arrolar de sítios como patrimônio universal pela Unesco até os contextos mais locais de reconhecimento de pequenos grupos sociais. A indexação crescente do patrimônio com a memória e o território fez com que essas noções se tornassem vetores de identidade e tivessem como projeto a garantia de continuidade dos que habitavam as localidades. No entanto, produziu como efeito uma identidade sempre inquieta, pois a todo momento, em busca de não ser apagada ou reprimida, era interpelada a tornar-se um valor turístico para obter investimentos econômicos que possibilitassem sua perpetuação. 


\section{Entraves ao reconhecimento patrimonial do Afoxé Filhos de Gandhi}

A indexação crescente entre memória, identidade e território, no entanto, foi justamente o que refreou os pleitos de reconhecimento da patrimonialização de alguns grupos que se posicionaram como perpetuadores da memória da Pequena África durante a reurbanização da região. Após a divulgação do plano Porto do Rio em 2001, movimentos sociais reivindicaram o pertencimento a determinados territórios e a legitimidade de suas formas habitacionais, vinculando-os discursivamente à herança afro-brasileira da cidade. Em suas manifestações públicas, eles compartilhavam de uma gramática performática específica: tocavam ritmos percussivos, realizavam rituais de candomblé e ofertavam comidas associadas à culinária negra, como feijoada, frango com quiabo, acarajé e angu. Mas o nível de reconhecimento obtido em face dos projetos de reurbanização da região variou de acordo com o vínculo legal que possuíam com suas habitações e seu estado se conservação.

Assim, algumas famílias praticantes do candomblé, apoiando-se em artigo constitucional que criou sujeitos políticos diferenciados a partir de autoidentificação étnico-racial, ${ }_{1}^{8}$ formaram em 2005 a Comunidade de Remanescentes do Quilombo da Pedra do Sal para reivindicar o direito de permanência em imóveis abandonados na região de propriedade de uma entidade católica. O conflito foi judicializado e defendido por organizações civis de apoio à habitação popular e às comunidades quilombolas, conseguindo como ação provisória a suspensão dos despejos que estavam sendo impetrados pela entidade contra o que classificavam como "invasores" (Guimarães 2013b, 2015). Já o Instituto de Pesquisa e Memória Pretos Novos foi criado em 2005 em sobrado na Gamboa, dez anos após a família residente descobrir um cemitério de escravos africanos a poucos palmos do piso, ${ }^{9}$ passando a obter gradualmente apoio governamental para prospecção arqueológica e difusão de conteúdo didático e cultural (Vassallo 2013).

O Afoxé Filhos de Gandhi, grupo identificado com a herança afro-brasileira, era o mais antigo da região portuária. Fundado no Rio de Janeiro em 1951, o bloco carioca foi inspirado no Ijexá Filhos de Gandhy, criado dois anos antes por estivadores de Salvador/BA em homenagem ao líder indiano Mahatma Gandhi. Religiosamente, o termo "afoxé" designava as saídas em cortejo das casas de candomblé para que filhos de santo depositassem oferendas aos orixás em mares, rios e matas, ou para que transportassem objetos sagrados de uma casa para outra. Aludindo a essa prática, o mesmo termo foi empregado por blocos carnavalescos que, ao se apresentarem recreativamente, tocavam o ritmo ijexá, cantavam em iorubá e dançavam 
coreografias dos orixás. Por isso, alguns chamavam o afoxé de "candomblé de rua". Além de utilizar o aparato ritualístico, performático e instrumental dos demais afoxés, o bloco baiano inseriu outros elementos que se tornaram marcas identitárias: o camelo como alegoria, o perfume de alfazema, longa veste e turbante brancos, colar nas cores azul e branco e a representação do líder indiano no desfile (Ipac 2010).

A sede do bloco carioca estava localizada desde 1997 em sobrado na área conhecida como Valongo, mas funcionava precariamente devido à avançada deterioração física do imóvel. No período pesquisado, ${ }^{10}$ os integrantes do Gandhi (como o bloco era chamado no dia a dia) moravam quase todos em bairros afastados das áreas central e portuária da cidade do Rio de Janeiro. Eram das camadas populares e atuavam profissionalmente em atividades diversas, como funcionário público, professor, inspetor escolar, enfermeira, taxista, artesão, cozinheira, faxineira, camelô. O bloco, no entanto, não era organizado unicamente por uma lógica de vizinhança, como ocorria em outras agremiações carnavalescas da cidade. Suas unidades de participação provinham principalmente das casas de candomblé, cujo coletivo também era denominado "povo do santo".

Na estrutura política do bloco eram responsabilidade do presidente e dos diretores o funcionamento da sede, a convocação de ensaios, a organização de desfiles e eventos e também a boa execução dos rituais religiosos. Suas atividades anuais dividiam-se em dois períodos complementares. Um iniciado em janeiro, com o maior "agrado" do ano para Exu, ${ }_{1}^{11}$ que operava como rito de calendário (Van Gennep 1960) ao inaugurar um tempo de intensa troca de dádivas e contradádivas com orixás, povo do santo, governantes, comerciantes, movimentos sociais e população. No dia seguinte, diversos integrantes do bloco se concentravam para o Presente de Iemanjá, cortejo religioso em que várias casas de candomblé tomavam as ruas do Centro pedindo proteção das iabás, designação dos orixás femininos, como Oxum, Nanã e Iansã. ${ }^{12}$ Logo depois, blocos afro e afoxés desfilavam na semana do Carnaval e os integrantes do Gandhi trajavam "lençóis" (como chamavam a longa veste branca), turbantes e colares nas cores azul e branco, marcas de sua identidade visual. ${ }^{13}$

Acabado o período momesco, o tempo era de dispersão dos desfilantes e da presença da diretoria do bloco em eventos políticos e culturais, como as comemorações do dia da Consciência Negra (20/11), do Samba (02/12) ou da Festa de Iemanjá do Mercadão de Madureira ${ }^{14}$ (30/12). A diretoria se apresentava com cerca de 15 músicos e dançarinos durante meia hora, às vezes recebendo modestos cachês que acentuavam o caráter mercantil da troca. Embora fossem eventos de pouca visibilidade midiática, para o 
Gandhi eram um importante meio de contatar pessoas de influência social e política que, em alguns casos, podiam até ganhar status especial e serem eleitos "presidente de honra" ou "madrinha" do bloco.

Como a sede do Gandhi estava deteriorada e não tinha uma situação habitacional considerada regular, houve por parte das instâncias governamentais uma persistente negação de seu direito de memória. O sobrado foi classificado como "ruína" por estudos de planejadores urbanos da Prefeitura (Sigaud \& Pinho 2000) e argumentos técnico-administrativos também afirmavam a impossibilidade de investir em imóveis "invadidos". Assim, mesmo localizada sobre o antigo local de comércio dos escravos africanos e abrigando uma expressiva manifestação cultural negra, a sede não foi incluída nos roteiros turísticos que exibiam os lugares de memória da Pequena África, nem considerada apta a receber projetos de conservação, reabilitação ou patrimonialização. Em abril de 2016, após toda a visibilidade do sítio arqueológico do Cais do Valongo, o bloco ainda utilizava redes sociais para pedir doações de material de obra e organizar mutirões para a melhoria das condições físicas e de limpeza da sede (https://www.facebook. com/Filhosdegandirjoficial).

O fracasso da demanda por reconhecimento do bloco explicitava, desse modo, o que e quem estavam sendo considerados patrimonializáveis durante a reurbanização da região portuária. Havia claramente um choque dos ideais humanistas de reconhecimento da diversidade cultural com a vertente de controle da "desordem urbana" do projeto urbano implantado pela Prefeitura e pelos demais parceiros governamentais e privados, classificação que incidia sobre diversas formas de ilegalidade, precariedade e informalidade. As "ruínas" do Gandhi, no entanto, eram a expressão material de um longo processo de deterioração de imóveis governamentais da região que foram desativados e abandonados. E para bem decifrá-las, era preciso compreender como os integrantes do bloco tinham construído em torno delas seus sentidos habitacionais e biográficos.

\section{Sentidos habitacionais e biográficos do sobrado da rua Camerino}

A obtenção de uma sede de ensaios era significativa tanto em relação à trajetória do bloco quanto ao tempo biográfico da diretoria presidida por Carlos Machado desde o ano 2000. Machado ${ }^{15}$ atribuía seu interesse inicial pelo bloco ao engajamento nas questões raciais e na organização comunitária dos bairros portuários. Ele não se identificava como detentor de "sangue negro nas veias", mas como "branco, descendente de portugueses e índios". 
Seu envolvimento com a cultura negra havia começado na década de 1970, quando era um jovem marinheiro e passou seis meses nos EUA no momento de projeção da liderança de Martin Luther King e de mobilização contra a segregação racial.

No Brasil, militou clandestinamente contra a ditadura militar e depois voltou suas energias para o resgate da escola de samba Vizinha Faladeira, sediada no Santo Cristo. Em 1985, já presidente da escola e diretor da Associação de Moradores e Amigos da Saúde, Machado foi procurado pelo então presidente do Gandhi, o Índio. Naquele ano, o processo de patrimonialização dos sobrados da região portuária pelo projeto Sagas estava movimentando debates locais e a intenção do bloco era obter a cessão de uso de um dos imóveis da região para instalar sua sede. Machado então indicou o sobrado que ficava na rua Camerino, ao lado do Jardim Suspenso do Valongo, um dos muitos imóveis abandonados na região pertencentes à Secretaria Estadual de Segurança Pública.

A partir do momento em que o sobrado se tornou objeto de desejo do Gandhi a narrativa de Machado ficou repleta de detalhes biográficos, evidenciando a importância que o espaço ganhou para o bloco. A primeira solicitação de cessão de uso foi arquivada e os ensaios do bloco passaram a ser realizados no Centro Cultural Municipal José Bonifácio, onde em 1988 Machado assumiu como diretor em decorrência da projeção política obtida após sua candidatura a vereador. A aproximação com o cotidiano do Gandhi fez com que começasse a participar da diretoria presidida por Guerra e juntos retomassem a negociação com o governo estadual.

Em 1992, "no apagar das luzes do governo Moreira Franco", o Gandhi conseguiu a cessão de uso do sobrado da rua Camerino por dez anos. O imóvel, no entanto, encontrava-se ocupado por algumas famílias, não havendo qualquer ação de reintegração de posse. Com a mudança do governo estadual, o sobrado foi novamente cedido, só que desta vez para a Prefeitura, que visava implantar ali o escritório técnico do Sagas. As famílias foram retiradas, mas o imóvel ficou lacrado e em 1997 a municipalidade decidiu devolvê-lo ao governo estadual. Antes que isso ocorresse, o bloco se apossou da sede, retirou todo o entulho que havia acumulado no terreno, pintou paredes, colocou correntes para fechar a porta e uma placa que o identificava como sede do Gandhi. Ainda que precariamente instalados, os cuidados com o sobrado fortaleceram o bloco para que apresentasse um novo pedido de cessão de uso.

No ano seguinte, Guerra ficou doente e pediu para Machado que assumisse a presidência do Gandhi. Ele recebeu com preocupação o pedido, já que não era iniciado no candomblé e passaria a ser sua responsabilidade 
proteger espiritualmente o conjunto dos integrantes do bloco. Para fortalecer seu orixá pessoal e assumir a presidência, ele então se iniciou aos 49 anos na casa do pai de santo Carlos, em Itaguaí, Baixada Fluminense. Assumiu o Gandhi em 2000, mas nem por isso se tornou frequentador assíduo de outras casas de candomblé. Sua autoridade continuou baseada na atuação carnavalesca e política em movimentos sociais da região portuária.

Em 2004, todos os imóveis da Secretaria Estadual de Segurança Pública foram transferidos para a Secretaria Estadual de Previdência Social, com o intuito de gerar recursos para o pagamento de aposentados e pensionistas. Iniciou-se então uma pressão para que os imóveis alugados abaixo do preço de mercado tivessem seus valores reajustados. O sobrado ocupado pelo Gandhi também foi taxado, com a apresentação de uma cobrança referente aos aluguéis dos anos anteriores. O bloco não possuía recursos para quitar a dívida e o governo não ofereceu qualquer garantia de que seria renovada a cessão de uso. Após inúmeras idas e vindas a secretarias estaduais para tentar negociar a dívida, Machado procurou o apoio da atriz Zezé Motta, então responsável pela Secretaria Estadual de Promoção da Igualdade Racial e convidada para ser "madrinha do bloco".

O sobrado foi prometido ao Gandhi e em 2008 iniciou-se a elaboração do projeto arquitetônico para a sua reforma. O imóvel estava então sem telhado, com vegetação alta e escada improvisada de madeira para o segundo andar. Mas ainda assim abrigava atabaques, vasos de plantas, roupas penduradas no varal, mesas, cadeiras, tinas para bebida, caixa de som e dois cachorros. Ali os homens da diretoria acendiam velas e tocavam para Exu na alvorada do Presente de Iemanjá, enquanto as mulheres confeccionavam os "balaios", cestos de palha ritualmente adornados para receber as oferendas das iabás. Era lá também que eles se encontravam para participar dos desfiles e realizar ensaios e reuniões.

O que as ruínas do sobrado mostravam, portanto, não era somente um processo de esquecimento ou o vestígio de um tempo impensado. O contínuo uso religioso e recreativo do bloco tinha tornado aquela edificação deteriorada um espaço habitado por humanos, orixás, plantas e animais. A presença dos diretores e dos desfilantes do bloco havia subvertido a ordem discursiva que insistia em afirmar o tempo da região portuária como abandonado e ultrapassado, conferindo ao sobrado outros significados, formas de habitar e experiências temporais. Reformar a sede seria apenas uma das tantas etapas do contínuo combate à destruição causada pela passagem do tempo (Rocha \& Eckert 2005).

Foi sob as tensões de despejo da sede e articulando os múltiplos e justapostos significados do sobrado - como ruína, como antigo comércio de 
escravos, como resistência cultural e como local de práticas recreativas e religiosas - que o bloco elaborou o projeto do Centro da Cidadania Afoxé Filhos de Gandhi, em parceria com o Instituto Batucadas Brasileiras (IBB), escola de música de ritmos percussivos instalada em sobrado na praça dos Estivadores, defronte à sede do bloco. O projeto previa a legalização e a reforma da sede; a criação de um "centro de memória" de divulgação do Gandhi e de "contribuição da população negra ao processo do desenvolvimento social do estado do Rio de Janeiro"; a criação de um "restaurante-escola voltado para a produção de pratos típicos da culinária de raiz africana", entre outras iniciativas voltadas para a geração de trabalho e renda (IBB \& Afoxé Filhos de Gandhi 2008).

Assim, depois de 23 anos tentando formalizar a ocupação do sobrado da rua Camerino, o bloco articulou um projeto baseado em seu reconhecimento como manifestação cultural. Para angariar apoio político, em 2009 o Gandhi organizou uma grande festa no sobrado com oferendas, louvações, discursos e feijoada. A festa contou com a presença de representantes governamentais, sambistas e povo do santo, mas não obteve os desdobramentos pretendidos. Durante e após o evento, críticas de filhos de santo e da "velha guarda" eram entreouvidas, acusando a diretoria do bloco de não seguir os fundamentos religiosos e de ter causado sua decadência carnavalesca. O fracasso em regularizar e reformar o imóvel era por eles atribuído aos espíritos dos africanos escravizados que, aguardando a realização do que consideravam ser rituais adequados, não estavam permitindo que "estranhos" conquistassem o espaço. Dessa forma, não só os critérios excludentes do governo e do mercado impediam a recuperação do sobrado, como também algo mais assombrava seus escombros.

\section{As disputas pela definição e controle dos bens simbólicos}

"Antigos ou velha guarda" eram termos utilizados por integrantes do Gandhi para se referirem aos diretores de gestões passadas que tinham boa reputação dentro da comunidade moral (Bailey 1971) formada pelas casas de candomblé, ou seja, entre aqueles que compartilhavam determinados valores e categorias para nomear as coisas do mundo social, natural e sobrenatural. Era a boa reputação religiosa que os legitimava para avaliar as práticas do bloco, a partir da evocação de um sentido de "verdade e genuinidade" em contraposição ao que percebiam ser "espúrio ou inautêntico". ${ }^{16}$

Durante a gestão de Machado, alguns antigos tinham se afastado das atividades da diretoria e entrado em guerra declarada pela sucessão pre- 
sidencial. E como no contexto de reurbanização da região portuária havia sido pleiteado o reconhecimento de um patrimônio específico ao Gandhi dentro da Pequena África, eles se puseram a defender o que entendiam ser a herança cultural do bloco. A partir da percepção de que a singularidade do Gandhi se devia a determinados mitos, ritos, objetos e lugares, a diretoria de Machado e antigos passaram a disputar quem teria a autoridade para definir quais bens eram simbolicamente valiosos para manter sua identidade e distinção diante de outras experiências coletivas. Bens que, por princípio, eram únicos, e por isso não podiam ser trocados ou vendidos (Weiner 1992).

Era através de mecanismos de linguagem e da autoridade centralizada da diretoria do bloco que tais bens se tornavam capazes de representar valores abstratos e experiências distantes no tempo e no espaço, mediando o mundo visível e o invisível, oposição que existiria "entre aquilo de que se fala e aquilo que se apercebe, entre o universo do discurso e o mundo da visão" (Pomian 1987:68). Podiam, dessa forma, evocar locais distantes como a África e a Bahia, tempos passados como o da escravidão africana e do trabalho negro na estiva, ou a conexão com orixás e espíritos dos antepassados do bloco. Como agentes de subjetivação, tais bens inventavam o bloco tanto quanto o bloco a eles, não sendo pensados apenas enquanto sinais diacríticos para a demarcação de diferenças sociais.

Esses bens, no entanto, não eram considerados fixos ou imutáveis. Justamente por serem investidos de importância simbólica, ao longo das gerações, mitos, ritos, objetos e lugares associados ao patrimônio do Gandhi eram postos em circulação ou transmutados com a intenção de produzirem uma expansão de suas relações sociais, o que trazia o risco de perda ou apropriação considerada indevida. Tais bens também podiam ser afetados por variações históricas e sociais de diferentes escalas, já que, ao circularem por diversas esferas de trocas da cidade, seus valores culturais eram constantemente reinterpretados a partir de outras lógicas, principalmente a da indústria turística (Clifford 1994; Kopytoff 2008).

A disputa pela definição e o controle desses bens simbólicos marcava os períodos de transição das autoridades do bloco, e seus fluxos tornavam aparentes quais configurações sociais e mentalidades estavam emergindo e quais estavam perdendo força. Mas o que todas as configurações de diretoria do bloco acabavam por enfrentar, em comum, era o dilema de manter a percepção de continuidade da identidade do Gandhi, de que o bloco permanecia o mesmo ainda que todos os seus membros saíssem ou fossem substituídos por outros. Pois, como bem lembra Halbwachs (2006), enquanto os bens durarem através do tempo, haverá também a permanência da memória coletiva. A tensão então estabelecida era a definição de um sistema 
de autenticidade que preservasse tais bens ao mesmo tempo que permitisse que outras lógicas fossem incorporadas às práticas do bloco.

Consegui contatar dois antigos que discordavam das práticas de Machado somente fora das atividades conduzidas pela diretoria, e a partir da mediação de um ogan que frequentava um ponto de venda de acarajé no Centro da cidade. ${ }^{17}$ Índio tinha sido presidente do Gandhi na década de 1980 e Hélio Tozan, o vice-presidente do falecido Guerra na década de $1990 .{ }^{18}$ Ambos eram vinculados a Pai Ninô de Ogum, ${ }^{19}$ liderança religiosa baiana cuja casa de candomblé instalada em Nova Iguaçu, Baixada Fluminense, havia concentrado todos os presidentes do bloco entre as décadas de 1970 e 2000, com a ruptura ocorrendo com a posse de Machado. Índio e Hélio, assim, haviam vivenciado suas experiências com o Gandhi dentro de uma casa de candomblé específica, que atuava como suporte físico e simbólico de suas memórias. Por isso, mesmo entrevistados separadamente, eles elaboraram narrativas semelhantes sobre acontecimentos, personagens e lugares associados ao passado do bloco.

O tempo era dividido por eles em unidades que denominavam "épocas" e correspondiam às gestões presidenciais do bloco. As épocas eram agrupadas em três períodos mais extensos: "origem", "fase áurea" e "decadência". Seus relatos eram organizadores também de espaços e, ao narrarem determinados percursos, produziam uma bricolagem simbólica entre casas de candomblé do Rio de Janeiro e da Bahia, escolas de samba cariocas e locais de trabalho e sociabilidade. Eram assim relatos performáticos, pois não só indicavam lugares, como também criavam culturalmente fronteiras simbólicas e físicas de pertencimento ao grupo vinculado à casa de Pai Ninô (De Certeau 2011). Através deles, Índio e Hélio classificavam a autenticidade de mitos, ritos, objetos e lugares, sobretudo em torno de dois aspectos entendidos como tradicionais: o domínio masculino (relacionado ao trabalho da estiva) e os fundamentos religiosos (relacionados ao candomblé).

\section{As transformações nos tempos e nos espaços masculinos e religiosos}

O mito de origem do Gandhi carioca remetia à fundação do bloco em 1951. Índio e Hélio não participaram do bloco nessa época, mas sabiam por relatos indiretos que a primeira formação tinha sido conduzida pelo falecido Le Paz, "carioca, negro, estivador e capoeirista, feito no santo no candomblé baiano do Axé Opô Afonjá". Os demais integrantes do bloco trabalhavam então atrás da Central do Brasil, terminal de transportes ferroviários e rodoviários que 
conectava bairros e municípios da região metropolitana ao Centro da cidade. Lá, eles faziam rodas de samba e capoeira e ofereciam serviços de pintor, pedreiro, marceneiro, ferramenteiro, chapeleiro, entre outros. Teria sido em uma segunda-feira de Carnaval que dois sapateiros baianos, ao sentirem saudades da terra natal, foram em casa buscar lençóis brancos. Cortaram um buraco para passar a cabeça, amarraram na cintura, penduraram seus atabaques e saíram acompanhados por mais nove homens pelas ruas cantando em ritmo ijexá a saudação ioruba: "Ê-emoriô. Ê-emoriô. Emoripaô". Depois, passaram a ensaiar no bairro da Gamboa, local de encontro dos baianos da estiva, e a desfilar pelas ruas do Centro e da região portuária.

Nesse Gandhi originário, a participação nos desfiles carnavalescos era exclusivamente masculina, tal como ocorria em Salvador. Bloco criado por trabalhadores da estiva, o Gandhi baiano trazia a forte presença do gênero masculino e a valorização da força física, já que nesse período o embarque e o desembarque dos produtos eram feitos artesanalmente e considerados um trabalho duro, insalubre e perigoso. A identidade de gênero dentro do bloco construiu-se dessa forma estritamente atrelada à identidade profissional e a um padrão de masculinidade baseado em noções como "virilidade e valentia", com rígidas normas de comportamento do que deveria ser um homem e, em contraste, uma mulher (Diéguez 2010).

A esse padrão de masculinidade foi justaposto o modelo de sexualidade observado no candomblé no qual, em analogia com o plano social mais amplo, homens e mulheres obedeciam a proibições rituais e o sexo masculino se distinguia em dois gêneros inconfundíveis: os "homens" e os "homossexuais ou bichas". Os homens seriam aqueles que atuavam no mundo terreno e também dos ancestrais, associados ao cultivado, à estrutura da sociedade e ao campo da ética e da disciplina moral. E os homossexuais seriam aqueles que se relacionavam com o mundo dos orixás, associado aos rituais de possessão e à estrutura da natureza e do feminino (Birman 1991).

Apesar de o Gandhi carioca ter sido predominantemente composto por profissionais dedicados a trabalhos manuais em que o uso da força física não era necessário, simbolicamente manteve-se a construção social do padrão de masculinidade dos estivadores e das divisões de gênero do candomblé. Suas relações sociais de sexo reproduziram então uma relação de poder que legitimava hierarquias e dinâmicas de dominação, ainda que permeadas de sentimentos de pertencimento, solidariedade e reconhecimento mútuos (Kergoat 2002).

Determinadas regras passaram a estruturar uma ordem social no bloco carioca em que o perigo de contato sexual expressava o domínio do princípio geral da masculinidade da estiva e do candomblé (Douglas 1976). Hélio e 
Índio sabiam assim que na formação do Gandhi não era permitido o desfile das mulheres, mas era solicitado que acompanhassem os homens ao final do bloco vestidas de "baianas", traje composto por bata, saia longa rodada e torsos brancos. Elas ajudavam a responder às cantigas de candomblé e também levavam bolsas, comidas, bebidas e armas para que fosse garantida a continuação da festa e das brigas após os desfiles. Suas participações eram, portanto, previstas, mas postas à margem da performance do bloco.

Ambos relataram um acontecimento que havia se tornado paradigmático por evidenciar, em forma de transgressão, a ordem social do bloco. Segundo Hélio, Dona Dulce teria sido a primeira mulher que, desejando evitar que o marido Le Paz se envolvesse com outras, conseguiu desfilar no Gandhi se vestindo de índio. Já de acordo com Índio, a primeira mulher a desfilar travestida havia sido Valdete, amante de Le Paz. Apesar da variação das versões, que demonstram o caráter indireto e oral da memória coletiva, as duas se encerravam com a descoberta do artifício e da restituição da ordem que entendia como certa (e segura) apenas a presença masculina nos desfiles.

Da segunda época do Gandhi, liderada a partir de 1961 pelo baiano e alfaiate Alberto Sales Pontes, esses antigos também só tinham uma lembrança indireta. Alberto era diretor da escola de samba Estação Primeira de Mangueira, morro da Zona Norte habitado por muitos baianos e filhos de santo, e havia produzido o estreitamento dos laços do bloco com o universo carnavalesco. Por seu intermédio, o Gandhi começou a ser convidado para compor alas nas escolas de samba quando havia um enredo simbolicamente indexado à cultura afro-brasileira e à escravidão, como nos desfiles da Acadêmicos do Salgueiro (Xica da Silva, 1963) e Portela (Tronco de Ipê, 1968). Homens de lençóis e mulheres de baianas então representavam juntos o bloco, mas o contato entre os sexos continuou proibido nos seus próprios desfiles.

A partir da década de 1970 as atividades do bloco foram vivenciadas diretamente por Índio e Hélio e demarcavam o que eles consideravam ser o início de sua fase áurea. Foi a época de Encarnação, presidente feito no santo em Salvador, na casa de Bate Folha, e ogan da casa de Pai Ninô, espaço religioso frequentado por esses antigos. Os desfiles do Gandhi dessa gestão teriam conseguido reunir cerca de 4 mil filhos de santo provenientes de diversas casas de candomblé da Baixada Fluminense. O aumento da popularidade do bloco também tinha feito com que fosse contratado pela Prefeitura para realizar a abertura oficial dos desfiles de Carnaval da cidade e para "apresentações culturais" no circuito folclórico, incentivado por mediadores intelectuais como o antropólogo e filho de santo Raul Lody. ${ }^{20}$

Foi a época de Encarnação que alterou o princípio da exclusividade masculina nos desfiles do bloco. Contudo, a mudança ocorreu de forma 
gradual e conciliatória, já que instaurou neles uma estrutura hierarquizada de alas. Inicialmente, "só as jovens filhas, sobrinhas e afilhadas" dos integrantes puderam desfilar fantasiadas de "escravas" (traje branco composto por alça ligada a saiote), o que manteve afastado o perigo de contágio com mulheres de vida sexual. Depois, passaram para dentro do desfile as mulheres vestidas de baianas, em ala que seguia ao final do bloco. Permaneceram com os homens o traje do lençol e o espaço frontal do desfile, garantindo o princípio da superioridade masculina em seu arranjo formal.

Os antigos consideravam que a fase áurea do Gandhi havia continuado mesmo após o falecimento de Encarnação em 1978, já que a presidência permaneceu por mais duas gestões com os frequentadores da casa de Pai Ninô. O período dirigido por Índio, no entanto, produziu o início das tensões entre preservação e disponibilização de práticas religiosas. Em sua gestão houve a primeira alienação de um bem associado ao candomblé: a permissão de não iniciados desfilarem no Gandhi. A justificativa de Índio se calcava na lógica de mercantilização do bloco: como ele tinha se transformado em "grupo folclórico", qualquer um poderia participar. Mas foi mantida sua direção pelos adeptos do candomblé, o que garantia a boa execução de seus rituais religiosos.

A heterogeneidade dos participantes, contudo, trouxe diferentes formas de conceber as participações do Gandhi nas escolas de samba, gerando como efeito a evidência dos homossexuais nos desfiles e o surgimento de "dissidentes". Segundo Índio, a primeira grande evasão do bloco teria ocorrido em 1982, quando a diretoria montou uma ala em uma grande escola de samba com figurino composto por vestido rendado e calçolão. No dia do desfile, alguns integrantes homossexuais apareceram vestindo só a roupa de renda e um tapa sexo, fazendo com que o jornalismo especializado pusesse em dúvida o caráter religioso do bloco por estar expondo corpos masculinos desnudos (a mostra dos seios das mulheres era permitida com o argumento de remeter às práticas africanas). Esses integrantes foram então repreendidos moralmente pela diretoria e se retiraram do Gandhi, formando o bloco afro Filhos de Dan. Era claramente o limite da alienação da tradição masculina do bloco, que havia aceitado a presença hierarquizada (e mercantilizada) das mulheres nos desfiles, mas não desejava ser associada a homossexuais, gênero oposto ao ideal de virilidade da estiva.

Ao final da época de Índio, em 1988, Guerra assumiu a presidência, iniciando a transição da fase áurea para a vivenciada por esses antigos como de decadência. Segundo Hélio, vice-presidente de Guerra, a fase gloriosa dessa gestão teria durado poucos anos, quando ainda participavam variadas casas de candomblé nos desfiles. O bloco também tinha mantido seu pres- 
tígio carnavalesco e havia conseguido pela primeira vez uma sede própria, através da cessão de uso em 1992 do imóvel da rua Camerino. Mas depois desse período, as narrativas de Hélio e Índio convergiam na rememoração de eventos de ruptura e conflito: Guerra adoeceu, a relação da diretoria com as casas de candomblé diminuiu, a velha guarda se afastou das atividades e o bloco não foi mais convidado a compor alas nas grandes escolas de samba.

Com a morte de Guerra, Machado assumiu a presidência, concretizando a perda do controle da direção religiosa do Gandhi pelos filhos de santo da casa de Pai Ninô. Segundo Hélio, Machado era bem-intencionado, mas "um estranho ao meio", por ser recém-iniciado no candomblé e vinculado mais às escolas de samba e aos movimentos sociais da região portuária do que às casas religiosas. Eles também atribuíam à época de Machado o fim da tradição masculina do Gandhi, já que sua gestão permitiu que mulheres usassem os lençóis nos desfiles e que homossexuais portassem o estandarte do bloco, o que desabonaria a conduta moral dos integrantes idealmente ligados à estiva e à capoeira. Esse sentimento era externado no comentário sobre uma apresentação cultural realizada defronte à Câmara de Vereadores, observada à distância por Hélio.

Porque o Gandhi antigamente era coisa de valente, era coisa de "homem, sim senhor", capoeirista, gente que dançava com o estandarte. Não se admitia homem de torcinho na cabeça [indumentária associada ao universo feminino], homem que não era homem dançando com o estandarte do Afoxé Filhos de Gandhi. Hoje o estandarte do Filhos de Gandhi, que sempre foi respeitado, hoje é elaborado por quem nós chamamos de "adé fontofe", homossexual. A gente não tem nada a ver com isso. Cada um na sua. Mas era tradição de não poder. Por exemplo, Gandhi em Salvador é coisa de estivador. Continua sendo gente de estiva, gente de Marinha, como era aqui a mesma coisa. E de repente, aqui no Rio, o Gandhi se perdeu. Ele se perdeu em todos os sentidos (Entrevista Hélio Tozan, 13 de novembro de 2009).

A poluição associada ao perigoso contato entre os diferentes sexos e gêneros era traduzida pela percepção de que males haviam se abatido sobre o Gandhi. Assim, nos relatos de Índio e Hélio, a época de Machado teria vivenciado um sistemático descumprimento de contratos de apresentação cultural, casos de roubo e desvio de verbas do bloco, atrasos e integrantes bêbados nos desfiles. O efeito dessa desordem social seria que, no contexto contemporâneo, já havia mais de 15 blocos afro dissidentes do Gandhi, formados por integrantes também ligados ao candomblé, que passaram a disputar adeptos religiosos e carnavalescos. 


\section{Dilemas da mercantilização dos patrimônios culturais}

Nas modernas sociedades ocidentais nunca houve uma distinção ontológica entre patrimônios culturais e mercado; pelo contrário, a atuação deste fez parte da constituição das coleções de bens inalienáveis, transformando símbolos de identidades em objetos economicamente valorizados e de interesse turístico (Gonçalves 2007). A mudança ocorrida após a década de 1980 no Brasil foi que a diversificação dos processos de patrimonialização retirou do comando do Estado a definição de que bens seriam considerados patrimônios e como eles seriam conservados e exibidos, tornando a participação do mercado mais explícita. Dessa forma, as transformações relativas aos domínios da masculinidade e da religiosidade na trajetória do Gandhi podem ser também interpretadas como parte inerente da profissionalização do carnaval carioca (Cavalcanti 1994) e da comercialização dos produtos associados ao candomblé (Sansone 2000), em um contexto mais amplo de consumo de bens culturais.

Por um lado, a ruptura com a casa de Pai Ninô D'Ogum e a revisão de valores sociais construídos em torno da tradição da estiva e do candomblé haviam desorganizado as noções de identidade e memória coletiva de alguns antigos. Mas, por outro, o próprio processo permanente de invenção carnavalesca possibilitou a emergência de outros agentes e lógicas de pertencimento, gerando tensões entre o que era passível de mudança e o que era considerado genuinamente gandhista e, portanto, idealmente um bem inalienável. Na recriação dos bens que poderiam ou não ser disponibilizados em troca de maior popularidade e recursos financeiros, um poderoso discurso obteve ressonância social: o multiculturalismo e suas pautas de tolerância e inclusão das chamadas minorias, entre elas mulheres e homossexuais. Desse contexto emergiu uma experiência compartilhada não pelos antigos, que se sentiram destituídos do controle religioso, político e moral do Gandhi, mas pela diretoria composta após a morte de Guerra, cujas ações eram pautadas pelo desejo de recolocar o bloco no competitivo mercado carnavalesco e também fortalecer os movimentos sociais da região portuária.

Após sua posse, Machado então começou um processo gradativo de mudança das letras das músicas do bloco do iorubá para o português e de aceleração de seu ritmo ijexá. Produziu ainda um desfile diferente das épocas anteriores, mantendo a organização do bloco em alas e o princípio da superioridade masculina, mas assimilando outras construções de gênero. A primeira ala do desfile continuou composta pelos homens que se apresentavam como músicos da charanga. Já a segunda foi dividida entre "machos" e "viados", termo usado para nomear os que durante o desfile utilizavam, 
além dos lençóis, adornos associados ao feminino, como o torço na cabeça reprovado no comentário de Hélio. Na terceira ala ficavam mulheres vestidas de lençóis. Elas também portavam uma série de objetos construtores da diferença de gênero, como maquiagem, sapatos de saltos altos, brincos e apliques capilares, e estavam sob especial controle para não exibirem acessórios e decotes que indicassem "luxo ou exibição". E ao final desfilavam as mulheres de baiana, traje associado apenas ao universo feminino. Ao longo do desfile todos os integrantes do bloco apresentavam um gestual comedido e eram inibidos os possíveis "excessos" comportamentais associados ao consumo de bebidas e drogas. Os diretores entendiam que essas restrições eram fundamentais na evocação dos aspectos religiosos do Gandhi e em sua diferenciação em relação a outros blocos afro. E buscavam reverter as acusações contra o que seriam as práticas desabonadoras de conduta moral do bloco apontadas pelos antigos.

Machado não considerava que transformando essas práticas estaria colocando em risco o patrimônio do Gandhi, já que sua gestão continuou comandada por filhos de santo e realizando o principal preceito antes das apresentações, que era o agrado para Exu. Em sua narrativa, uma versão diferente da autenticidade do bloco era articulada: pouco importavam o trabalho na estiva e o circuito de candomblé formado em torno de Pai Ninô. A memória coletiva que passou a predominar era ancorada materialmente nos espaços dos movimentos sociais e carnavalescos da região portuária e referenciada em eventos, personagens e lugares considerados por eles importantes, como a Pequena África.

Assim, quando em 2003 convocou novas eleições para o bloco, além de sua chapa mais quatro se inscreveram. Machado obteve pouco mais da metade dos votos, embora sob denúncias de ter convocado a vizinhança dos bairros portuários para votar. Por sua vez, ele rebatia tais acusações afirmando que as outras três chapas levaram para votar frequentadores das casas de candomblé que nunca haviam desfilado no Gandhi, com o único intuito de impedir sua vitória. Era claramente o embate entre dois tipos preponderantes de vínculos identitários: o "carnavalesco e da região portuária" versus o "estivador e da casa de Pai Ninô" - ambos componentes da trajetória do bloco, mas que naquele contexto haviam se polarizado.

O acirramento dessas diferentes concepções de patrimônio foi um dos fatores que fizeram com que, mesmo tendo mais de meio século de existência, o bloco ficasse à margem da identificação e da patrimonialização da herança africana do porto, pois impediu que obtivesse apoio expressivo das casas religiosas. Na percepção dos antigos, só se o bloco retornasse à direção da "família de Encarnação" - expressão que se referia tanto aos seus 
parentes consanguíneos quanto aos de santo - é que o Gandhi voltaria para seus legítimos herdeiros e se regeneraria. Mas nada indicava que isso iria ocorrer. Pelo contrário, continuava intensa a circulação dos bens do bloco entre diferentes contextos históricos, sociais e políticos, já surgindo intenções explícitas de na próxima eleição ser apresentada uma chapa presidida por uma mulher. Ficava assim cada vez mais difícil estabilizar memórias e transformá-las em políticas governamentais e artefatos a serem exibidos.

Recebido em 25 de outubro de 2015

Aprovado em 08 de junho de 2016

Roberta Sampaio Guimarães é professora adjunta e pesquisadora do Departamento de Antropologia e do Programa de Pós-Graduação em Ciências Sociais da Universidade do Estado do Rio de Janeiro, Rio de Janeiro/RJ, Brasil. E-mail: <guimaraes_45@yahoo.com.br>

\section{Notas}

1 Os dados apresentados neste artigo foram, em sua maioria, coletados durante a realização de minha tese de doutorado (Guimarães 2011a, 2014) a partir de observação participante, entrevistas, registros fotográficos e audiovisuais de locais e eventos, e consultas a arquivos públicos e produtos de comunicação como jornais, filmes e obras literárias. No processo de análise desses dados, foram fundamentais a orientação de José Reginaldo Gonçalves e os debates no Laboratório de Antropologia de Arquitetura e Espaços (Laares). Foram ainda importantes na elaboração deste texto a leitura e os comentários de João Paulo Castro e as sugestões dos pareceristas anônimos da revista.

2 Os arqueólogos do Museu Nacional que trabalharam nas escavações ganharam destaque no processo de classificação e exibição dos vestígios materiais do cais do Valongo. Segundo relatos da equipe da arqueóloga Tania Andrade Lima, eles se sentiram limitados para proceder à identificação do material coletado no cais, chamando para auxiliá-los religiosos de matriz africana (O Globo, 21/09/2014).

3 Como apontam Vassallo e Cicalo (2015), para obter a unanimidade exigida pela Unesco para a candidatura do Cais do Valongo como patrimônio da humanidade, a Prefeitura envolveu diversos intelectuais e lideranças sociais e religiosas ligadas à identidade afro-brasileira. Tornou-se então essencial a mediação dos representantes de agências governamentais promotoras de políticas de igualdade e valorização da cultura negra na condução do Grupo de Trabalho Curatorial, como o Conselho 
Municipal de Defesa dos Direitos do Negro (Comdedine), a Superintendência de Promoção da Igualdade Racial (Supir), a Coordenadoria Especial de Políticas Pró-Igualdade Racial (Ceppir), a Fundação Cultural Palmares e o Conselho Estadual de Defesa dos Direitos do Negro (Cedine).

4 As gestões municipais que implementaram o conceito de projeto urbano no Rio de Janeiro foram comandadas sucessivamente por César Maia (1993-1996), Luiz Paulo Conde (1997-2000), César Maia (2001-2008) e Eduardo Paes (2009-2016).

5 Esse imaginário foi produzido e difundido por reportagens jornalísticas cotidianas e diferentes produtos mediadores, como o livro-reportagem Cidade partida, de Zuenir Ventura (1994); os filmes Notícias de uma guerra particular, de Katia Lund e João Moreira Salles (1999), e Orfeu, de Cacá Diegues (1999); e o romance Cidade de Deus, de Paulo Lins (2001).

6 As designações espaciais utilizadas neste artigo, como favela, subúrbio, Zona Portuária, Centro, Zona Norte e Zona Sul, são baseadas em usos nativos ou fontes literárias. Não pretendem, assim, discutir ou reificar noções ideológicas de descrição e análise da realidade.

7 O livro foi publicado como resultado de um concurso de monografias sobre personalidades ligadas à música popular brasileira realizado pela Funarte, órgão vinculado ao Ministério da Cultura. Segundo reportagem publicada no Estado do Paraná (08/04/1980), o primeiro concurso do órgão se deu em 1977 e teve como tema o músico Pixinguinha. Outras monografias foram feitas até que selecionaram Tia Ciata como tema do concurso de 1980. A primeira edição do livro foi publicada em 1983 pela própria Funarte e em 1995 o livro foi reeditado e expandido pela Prefeitura do Rio de Janeiro, com a inclusão do capítulo "Geografia musical da cidade".

8 A trajetória política do termo "comunidade de remanescentes de quilombo" remonta ao contexto brasileiro de discussões raciais da década de 1980, quando foi aprovado pela Constituição Federal de 1988 artigo que criava sujeitos políticos diferenciados com direito à propriedade definitiva das terras que estivessem ocupando através da emissão de títulos de reconhecimento étnico pelo Estado (Arruti 2006).

9 Os ossos encontrados eram de africanos que haviam morrido durante a viagem de navio ou logo após sua chegada no porto, tendo sido enterrados numa vala coletiva pelo governo colonial (Pereira 2007).

10 Entre junho de 2008 e novembro de 2009, acompanhei as atividades da diretoria, as principais festividades do bloco, além de realizar conversas informais e três entrevistas de longa duração: com o presidente do bloco, Carlos Machado, e com dois integrantes da "velha guarda", Índio e Hélio Tozan. Participei ainda das festas para os orixás da casa de Marlene D'Oxum, mãe de santo atuante no bloco.

11 O agrado para Exu era definido pelo presidente do bloco, Carlos Machado, como uma troca de energia com os orixás. Exu então enviava para Ogum um pedido 
de proteção dos integrantes do bloco contra qualquer violência ou tumulto ao longo das festas carnavalescas.

12 No cortejo, o bloco se unia ao povo do santo defronte à Câmara de Vereadores, onde líderes religiosos entoavam músicas que faziam referência aos orixás e proferiam discursos em prol da valorização da cultura negra e das leis de punição da intolerância religiosa. Depois, todos rumavam para o terminal marítimo da Praça XV e despejavam as oferendas nas águas da baía de Guanabara. O cortejo era registrado por redes de televisão, jornais e revistas, produzindo visibilidade e afirmando as práticas do candomblé diante da população da cidade (Guimarães 2011b).

13 Em 2009, o Gandhi desfilou com cerca de 300 integrantes. O maior desfile ocorreu na avenida Rio Branco, no Centro da cidade, encerrando o dia reservado pela Prefeitura para a apresentação de afoxés e blocos afros. Embora os dois tipos de grupo musical fossem referenciados na cultura afro-brasileira, diferentes dos afoxés, os blocos afro cantavam somente músicas em português, não seguiam os fundamentos do candomblé em suas apresentações nem tocavam ijexá.

14 O Mercadão de Madureira é um centro de comércio popular com lojas de produtos diversos. A Festa de Iemanjá é organizada por lojistas de artigos de candomblé e umbanda no dia 29 de dezembro e desloca, em carreata, centenas de devotos para depositar suas oferendas na praia de Copacabana (Martins 2009).

15 Machado foi entrevistado por mim nos dias 23 e 25 de novembro de 2008. Agradeço a ele a longa convivência que tive com o bloco e também aos diretores e frequentadores assíduos Nato, Galeto, Cabeça Branca, Cotoquinho, Regina, Carlinhos, Tia Creusa, Mãe Marlene, Juan, Luan e Nazaré, Márcia e Gustavo.

16 Uma ampla literatura problematiza o uso do termo "autenticidade" associado à ideia de verdade, genuinidade e intimidade. Seja se referindo a objetos de arte, experiências turísticas ou a bens culturais que compõem os patrimônios culturais, estudiosos como Benjamim (1994), Handler (1985) e Gonçalves (1996) questionam a utilização da noção como algo imanente ao próprio objeto de estudo.

17 O ogan Wilson Silva era frequentador assíduo do ponto de venda da Ciça do Acarajé na Praça XV e amigo da antropóloga Nina Bitar, pesquisadora das práticas e apropriações dos espaços públicos da cidade pelas baianas de acarajé (Bitar 2011). Agradeço aos dois pela possibilidade do encontro.

18 As entrevistas foram realizadas separadamente no dia 13 de novembro de 2009, ambas com a presença de Wilson Silva.

19 Pai Ninô instalou sua casa de candomblé no Rio de Janeiro no início da década de 1940. Dados biográficos estão disponíveis no Museu da Imagem e do Som (em entrevista de 1994 realizada pelo projeto A voz do Povo do Santo) e no Iphan (em entrevista de 2007 do projeto Mapeamentos de Terreiros de Candomblé no Estado do Rio de Janeiro), como indica Silveira (2012). 
20 Raul Lody era carioca, mas ainda jovem havia sido confirmado no santo em Salvador. Ele se tornou frequentador do bloco carioca e auxiliou sua contratação por agências governamentais para apresentações do Rio de Janeiro e em outros estados, como Minas Gerais, Paraíba e Alagoas. Foi ele também quem produziu o primeiro suporte material das memórias do bloco: um estudo publicado durante a Campanha de Defesa do Folclore do Ministério da Educação e Cultura, em que descrevia algumas das práticas culturais e características religiosas da época de Encarnação (Lody 1976).

\section{Referências bibliográficas}

ALBERTI, Verena \& PEREIRA, Amilcar. 2007. "Significados da África para o movimento negro do Brasil". Estudos Históricos, 39:25-56.

ARRUTI, José Maurício. 2006. Mocambo: antropologia e história do processo de formação quilombola. São Paulo: Edusc.

BAILEY, Frederick. 1971. Gifts and poison: the politics of reputaition. Oxford: Basil Blackwell.

BARANDIER, Henrique. 2006. "Projeto urbano no Rio de Janeiro e as propostas para a área central nos anos 1990". In: R. C. Silva (org.), A cidade pelo avesso: desafios do urbanismo contemporâneo. Rio de Janeiro: Viana \& Mosley/ PROURB. pp. 145-167.

BENJAMIM, Walter. 1994. "A obra de arte na era de sua reprodutibilidade técnica". In: Magia e técnica, arte e política: ensaios sobre literatura e história da cultura (Obras escolhidas, v. 1). São Paulo: Brasiliense. pp. 165-196.

BIRMAN, Patrícia. 1991. "Relações de gênero, possessão e sexualidade". Physis. Revista de Saúde Coletiva, 1(2):37-57.

.; FERNANDES, Adriana \& PIEROBON, Camila. 2014. "Um emaranhado de casos: tráfico de drogas, estado e precariedade em moradias populares". Mana. Estudos de Antropologia Social, 20(3):431-460.
BITAR, Nina. 2011. Baianas de acarajé: comida e patrimônio no Rio de Janeiro. Rio de Janeiro: Editora Aeroplano.

BORDENAVE, Geisa. 2014. A antiga fábrica da Bhering. Novos usos do espaço e manifestações artísticas na Zona Portuária do Rio de Janeiro. Dissertação de Mestrado, Programa de Pós-Graduação em Ciências Sociais, Universidade do Estado do Rio de Janeiro, Rio de Janeiro.

CARVAlHO, José Murilo. 2001. Os bestializados. O Rio de Janeiro e a República que não foi. São Paulo: Companhia das Letras.

CAVALCANTI, Maria Laura. 1994. Carnaval carioca: dos bastidores ao desfile. Rio de Janeiro: UFRJ.

CHAlHOUB, Sidney. 1996. Cidade febril. Cortiços e epidemias na Corte Imperial. São Paulo: Companhia das Letras.

CLIFFORD, James. 1994. "Colecionando arte e cultura". Revista do Patrimônio, 23:69-89.

COMPANS, Rose. 1998. "Parceria público-privada na renovação urbana da Zona Portuária do Rio de Janeiro". Cadernos IPPUR, 12(1):79-105.

DE CERTEAU, Michel. 2011. A invenção do cotidiano. Rio de Janeiro: Vozes.

DIÉGUEZ, Carla Regina. 2010. "A masculinidade do trabalhador portuário: novas questões em tempo de auto- 
mação". Fazendo Gênero, 9. Anais do Seminário Internacional Fazendo Gênero 9 - Diásporas, diversidades, deslocamentos Santa Catarina. Mimeo.

DOUGLAS, Mary. 1976. Pureza e perigo. São Paulo: Perspectiva.

FOUCAULT, Michel. 2001. "Outros Espaços". In: Ditos e escritos. Vol. III. Rio de Janeiro: Forense. pp. 411-422. GONÇALVES, José Reginaldo. 1996. A retórica da perda: os discursos do patrimônio cultural no Brasil. Rio de Janeiro: UFRJ / IPHAN. . 2007. "Os limites do patrimônio". In: M. F. Lima Filho; C. Eckert \& J. Beltrão (orgs.), Antropologia e patrimônio cultural: diálogos e desafios contemporâneos. Blumenau: ABA/ Nova Letra. pp. 239-248.

GORELICK, Adrián. 2005. Das vanguardas a Brasília: cultura urbana e arquitetura na América Latina. Belo Horizonte: UFMG.

GUIMARÃES, Antonio Sergio. 2001. "Democracia racial: o ideal, o pacto e o mito". Novos Estudos Cebrap, 61:147-162.

GUIMARÃES, Roberta. 2011a. A utopia da Pequena África. Os espaços do patrimônio na Zona Portuária carioca. Tese de Doutorado, Programa de Pós-Graduação em Sociologia e Antropologia Universidade Federal do Rio de Janeiro, Rio de Janeiro. . 2011b. "Entre vulgarizações e singularizações: notas sobre a vida social dos balaios". Horizontes Antropológicos, 17:127-143.

. 2013a. "O encontro mítico de Pereira Passos com a Pequena África: narrativas de passado e formas de habitar na Zona Portuária carioca". In: J. R. S. Gonçalves; R. S. Guimarães \& N. P. Bitar (orgs.), A alma das coisas. Patrimônio, materialidade e ressonância. Rio de Janeiro: Mauad. pp. 47-78.
. 2013b. "Urban interventions, memories and conflicts: Black heritage and the revitalization of Rio de Janeiro's Port Zone". Vibrant, 10:208-227. . 2014. A utopia da Pequena África. Projetos urbanísticos, patrimônios e conflitos na Zona Portuária carioca. Rio de Janeiro: FGV.

. 2015. "A arquitetura de um espaço franciscano em tempos de reurbanização do porto carioca". Religião e Sociedade, 35(1):87-106.

. 2016. "O patrimônio cultural da gestão dos espaços do Rio de Janeiro". Estudos Históricos, 29(57):147166.

GUTTERRES, Anelise. 2014. A resiliência enquanto experiência de dignidade: antropologia das práticas políticas em um cotidiano de lutas e contestações junto a moradoras ameaçadas de remoção nas cidades sede da Copa do Mundo 2014 (Porto Alegre, RS e Rio de Janeiro, RJ). Tese de Doutorado, Programa de Pós-Graduação em Antropologia Social, Universidade Federal do Rio Grande do Sul, Rio Grande do Sul.

HALBWACHS. 2006. A memória coletiva. Rio de Janeiro: Biblioteca Vértice/ Revista dos Tribunais.

HANDLER, Richard. 1985. "On having a culture". In: G. Stocking (org.), Objects and others: essays on museums and material culture. Madison: The Winconsin University Press. pp. 192-217.

HARTOG, François. 2006. "Tempo e patrimônio". Varia Historia, 22(36):261273.

HUYSSEN, Andreas. 2000. Seduzidos pela memória: arquitetura, monumentos, mídia. Rio de Janeiro: Aeroplano.

IPAC. 2010. Desfile de afoxés. Salvador: Fundação Pedro Calmon. 
JACOBS, Jane. 2011. Morte e vida de grandes cidades. São Paulo: Martins Fontes.

KERGOAT, Danièle. 2002. "A relação social de sexo. Da reprodução das relações sociais à sua subversão. Pro-Posições, 13(37):47-59.

KOPYTOFF, Igor. 2008. "A biografia cultural das coisas: a mercantilização como processo". In: A. Appadurai (org.), A vida social das coisas. As mercadorias sob uma perspectiva cultural. Niterói: Eduff. pp. 89-121.

LEITE, Marcia. 1995. “Da metáfora da guerra à mobilização pela paz: temas e imagens do Reage Rio". Cadernos de Antropologia e Imagem, 4:121-145.

LODY, Raul. 1976. Afoxé. Caderno de Folclore 7. Rio de Janeiro: MEC/ Campanha de Defesa do Folclore Brasileiro.

MARTINS, Ronaldo Luiz. 2009. Mercadão de Madureira: caminhos de comércio. Rio de Janeiro: Condomínio do Entreposto Mercado do Rio de Janeiro.

MOURA, Roberto. 1995. Tia Ciata e a Pequena África no Rio de Janeiro. Rio de Janeiro: Funarte.

NORA, Pierre. 1993. "Entre memória e história: a problemática dos lugares". Projeto História, 10:7-28.

PACHECO DE OLIVEIRA, João. 2014. "Pacificação e tutela militar na gestão de populações e territórios". Mana. Estudos de Antropologia Social, 20(1):125-161.

PEREIRA, Júlio César. 2007. À flor da terra: o cemitério dos pretos novos no Rio de Janeiro. Rio de Janeiro: Garamond/IPHAN.

POMIAN, Krzysztof. 1987. "Coleção". In: R. Ruggiero (org.), Enciclopédia Einaudi. Memória-História. Porto:
Imprensa Nacional/Casa da Moeda. pp. 51-86.

ROCHA, Ana Luiza da \& ECKERT, Cornélia. 2005. O tempo e a cidade. Porto Alegre: UFRGS.

SANSONE, Livio. 2000. "Os objetos da identidade negra: consumo, mercantilização, globalização e a criação de culturas negras no Brasil". Mana. Estudos de Antropologia Social, 6(1):87-119.

SIGAUD, Márcia \& PINHO, Claudia Maria. 2000. Morro da Conceição: da memória o futuro. Rio de Janeiro: Sextante/PCRJ.

SILVEIRA, Leandro. 2012. Nas trilhas de sambistas e "povo do santo": memórias, cultura e territórios negros do Rio de Janeiro (1905-1950). Dissertação de Mestrado, Universidade Federal Fluminense, Programa de Pós-Graduação em História, Niterói, Rio de Janeiro.

VAN GENNEP, Arnold. 1960. The rites of passage. Chicago: The University of Chicago Press.

VASSALLO, Simone. 2013. "Releituras da escravidão negra e da Zona Portuária do Rio de Janeiro: o caso do Instituto dos Pretos Novos". In: G. Pontes Jr.; M. Sepúlveda dos Santos; R. Souza \& V. H. Pereira (orgs.), Cultura, memória e poder: diálogos interdisciplinares. Rio de Janeiro: Eduerj. pp. 83-92.

. \& CICALO, André. 2015. "Por onde os africanos chegaram: o Cais do Valongo e a institucionalização da memória do tráfico negreiro na região portuária carioca". Horizontes Antropológicos, 21(43):239-271.

WEINER, Annette. 1992. Inalienable possessions: the paradox of keepingwhile-giving. Berkeley: University of California Press. 


\section{Entrevistas}

Carlos Machado, 23 e 25 de novembro de 2008.

Hélio Tozan, 13 de novembro de 2009.

Índio, 13 de novembro de 2009.

\section{Jornais e sites consultados}

Estado do Paraná. Aramis Millarch, "Lúcio Rangel dá nome para estimular a MPB", 08 de abril de 1980. Disponível em: http://www.millarch. org/artigo/lucio-rangel-da-nome-para-estimular-mpb. Acesso em 14/02/2009.

O Globo. Simone Candida, "Tania Andrade Lima, a arqueóloga que desenterrou a história do Cais do Valongo", 21 de setembro de 2014, Rio. Disponível em: http://oglobo.globo.com/rio/ tania-andrade-lima-arqueologa- -que-desenterrou-historia-do-cais-do-valongo-14002079. Acesso em 26/02/2016.

\section{Sites consultados}

PORTO MARAVILHA. Circuito de Celebração da Herança Africana. Disponível em: http://portomaravilha.com. br/web/esq/projEspHeranca.aspx. Acesso em ago. 2015.

UNESCO. Proposta de candidatura do Sítio Arqueológico Cais do Valongo. Disponível em: http://whc.unesco. org/en/tentativelists/5877/. Acesso em nov. 2014.

\section{Outras fontes}

IBB e Afoxé Filhos de Gandhi. Centro de Cidadania Afoxé Filhos de Gandhi. 2008. Material de circulação interna. 


\section{PATRIM ÔNIOS E CONFLITOS DE UM AFOXÉ NA REURBANIZAÇÃO DA REGIÃO PORTUÁRIA CARIOCA}

\section{Resumo}

Neste artigo, reflito sobre os efeitos da reurbanização da região portuária carioca sobre o Afoxé Filhos de Gandhi, bloco carnavalesco referenciado nas práticas do candomblé. Busco compreender como o bloco organizou um pleito de reconhecimento patrimonial a partir da construção narrativa da Pequena África na tentativa de regularizar e reformar o sobrado de sua sede de ensaios, mas não encontrou apoio governamental ou privado porque o imóvel foi classificado como "em ruínas e invadido". Exploro a hipótese de que o não reconhecimento se deveu, por um lado, ao fato de que esses setores privilegiaram investir em narrativas sobre um passado mítico relacionado à oralidade e à religiosidade africanas, o que dissociava as ações patrimoniais e turísticas das demandas habitacionais do tempo presente. Mas se deveu também a disputas dos integrantes do bloco sobre suas concepções de patrimônio, que reverberavam diferentes experiências e memórias coletivas do "povo do santo".

Palavras-chave: Patrimônio cultural, Projeto urbano, Candomblé, Carnaval, Afoxé Filhos de Gandhi, Rio de Janeiro.

PATRIM ONIOS Y CONFLICTOS DE UN AFOXÉ EN LA REURBANIZACIÓN DE LA REGIÓN PORTUARIA CARIOCA

\section{Resumen}

En este artículo reflexiono sobre los efectos de la reurbanización de la región portuaria carioca sobre el Afoxé Filhos de Gandhi, bloco carnavalesco referenciado en las prácticas de candomblé. Busco comprender como el bloco organizó un pleito de reconocimiento patrimonial a partir de la construcción narrativa de la Pequeña África en el intento de regularizar y reformar la terraza de su sede de ensayos, pero no encontró apoyo gubernamental o privado porque el inmueble fue clasificado como "en ruinas e invadido". Exploro la hipótesis de que el no reconocimiento se debió, por un lado, al hecho de que estos sectores privilegiaron invertir en narrativas sobre un pasado mítico relacionado a la oralidad y la religiosidad africanas, lo que disociaba las acciones patrimoniales y turísticas de las demandas habitacionales del tiempo presente. Pero se debió también a disputas de los integrantes del bloco sobre sus concepciones de patrimonio, que reverberaban diferentes experiencias y memorias colectivas del "pueblo de santo".

Palabras-clave: Patrimonio cultural, Proyecto urbano, Candomblé, Carnaval, Afoxé Filhos de Gandhi, Rio de Janeiro.

\section{HERITAGE AND CONFLICTS OF AN AFOXÉ IN THE REURBANIZATION OF THE PORT OF RIO DE JANEIRO}

\section{Abstract}

In this article, I reflect on the effects of the reurbanization of Rio's port area on the Afoxé Filhos de Gandhi, a carnival group rooted in Candomblé practices. I seek to understand how the group prepared a claim to heritage status through the narrative construction of 'Little Africa', in an attempt to regulate and reform the large house they were based in. However, they 
met with no government or private support because the property was classified as "ruined and occupied". I explore the hypothesis that this non-recognition was partly due to the fact that these sectors invested in narratives about a mythical past related to orality and African religion, which dissociated heritage and tourism from the housing demands of the present. But it was also due to internal disputes within the group's membership about their own concepts of heritage, disputes that, in turn, reverberated different experiences and collective memories of the "holy people".

Keywords: Cultural heritage, Urban Project, Candomblé, Carnival, Afoxé Filhos de Gandhi, Rio de Janeiro. 